\title{
Integrating play-based approaches into nursing education: Teachers as playful academics
}

Belinda J. Dean $a$ and Judi A. Parson $b$

Deakin University, Australia.

$a$ RN, BN, MCPT, Deakin University, Geelong 3220, Australia

$b$ RN, BN, Ma. Play Therapy, PhD, Deakin University, Geelong 3220, Australia

\section{ARTICLE INFO}

Article history:

\section{Keywords:}

\section{Play}

Playful Teaching

Play Based Learning

Play Pedagogy

Higher Education

Playful Andragogy

Role Play

Projective Play

Pretend Play

\section{A B S T R A C T}

The integration of play pedagogy is central to childhood education; however, it is also relevant to adult education (andragogy). In higher education, playful approaches are challenging for some academics because play could be considered childish when serious nursing topics are described and explored. Nevertheless, integrating playful andragogy may lead to improved educational outcomes by including the art and science of play therapy techniques within teaching scholarship. The use of these play-based approaches in teaching are powerful because play is recognised as the change agent to facilitate communication, including both direct and indirect teaching. Play also enhances creative problem solving, social relationships, empathy, and self-esteem, which are crucial skills for nurses to develop. Innovative play-based education employing, for example, games, puppets and dramatic role-play activities, is evidenced in the literature. Furthermore, projective, small world play in the teaching of nursing concepts has had a significant positive effect on student learning outcomes. In small world play, miniature replicas of people, animals, buildings, furnishings and other relevant toys are utilized to simulate real life medical scenarios.

The nursing academic who is responsible for setting the playful conditions, creates a safe and permissive learning environment, which in turn facilitates the student's ability to engage in fun exploratory learning activities. It is hypothesised that the use of a humanistic stance with playful engagement, such as projective small world play, will facilitate optimal teaching conditions in the higher education sector.

Published under Creative Commons License 4.0 


\section{Introduction}

Academics set the conditions for the learning environment and are in a strong position to engage students in creative ways of teaching, which in turn facilitate optimal skill development and knowledge acquisition to enter an occupation. In nursing, students have a full and rigorous curriculum which demands combining the art and science of the profession within a multidisciplinary workforce. The Registered Nurse (RN) is prepared through the higher education system and this paper is focused on the teaching and learning of their education as opposed to other levels of nursing qualifications. The International Council of Nurses (ICN) (2008) defines nursing as both a collaborative and autonomous role in caring for people and groups of all ages, sick and well, and in various settings. Nursing also involves health promotion, illness prevention, advocacy, research, and education (International Council of Nurses, 2008). In order to undertake such a broad role, graduate nurses are required to develop a range of discipline-specific knowledge and capabilities, as well as generic skills in relation to communication; digital literacy; critical thinking; problem solving; self-management; team-work; and global citizenship, which are integrated into the course design (Deakin University Graduate Learning Outcomes, 2020). Therefore, curriculum alignment and andragogic considerations are reviewed to optimise student engagement and we encourage academics to consider how and when to integrate more creative and playful ways to facilitate student's learning. The authors of this paper are both registered nurses and play therapists working in academia and have a play-based lens from which to view andragogy.

Andragogy is the theoretical and practical approach to adult learning (Knowles, 1984). Knowles places the adult centre stage within their learning experience and is based on humanistic thinking, where the adult is considered autonomous in their learning and teachers are facilitators. This approach is important for when playful academics design learning activities because adult learners: need to know the justification for learning specific content; learn experientially in a meaningful way; approach learning as problem-solving; and learn best when the topic is taught when required within the scaffolded curriculum (Culatta, 2020).

Further to Knowles' (1984) andragogy, and associated within a humanistic stance, Carl Rogers also positions the student at the centre within the learning process. Rogers (1969) aligned person-centred therapy with student-centred approaches in education, whereby the educator uses their humanistic skills, such as unconditional positive regard, empathy, and congruence, to facilitate the student's acquisition of knowledge, skills and reflexivity. The playful academic demonstrates a student-centred stance in order to create optimal learning conditions and incorporates play-based teaching when appropriate.

Andragogic and humanistic teaching strategies could incorporate, for example, case studies, role playing, simulations, and self-evaluation. During practical instructions, the playful academic adopts the role of an approachable facilitator, in contrast to the historical perception of a hierarchical power structure between professor and student. Furthermore, when feedback for written assessments is required, the playful 
academic uses unconditional positive regard and empathy to frame responses, which promotes the attitude towards the students as respected adult learners.

Two ways to create play-based teaching are to combine the principles of andragogy and the student-centred approach with either the Embodiment-Projective-Role (EPR) play development (Jennings, 1999) and/or the Therapeutic Powers of Play (TPoP) (Schaefer \& Drewes, 2014). The authors assert that play can inform teaching methods and these are explored below to inform the playful academic. Firstly, the background to nursing and nursing education sets the scene to explore play and the integration of play methods within the higher education sector.

\section{Background to nursing education}

Within the Australian context, nursing has evolved from hospital-based apprenticeship style training to become a professional higher education degree (Commonwealth of Australia, 2013). The transition to university teaching was based on establishing a clear delineation of scope of nursing practice through research to further develop the body of evidenced-based nursing practice knowledge (Commonwealth of Australia, 2013; Mackey \& Bassendowski, 2017). University education has a strong curriculum focusing on technical skills and linking theory to practice (Margaret, Jennene, Madsen, \& Godden, 2010). The congested curriculum often results in teaching practices that are weighted heavily on developing nursing students who can undertake clinical tasks to support the physical health of patients; across a wide range of presenting diagnoses, issues and concerns; and across the human lifespan. Therefore, it is imperative that nurses provide and abide by ethical and safe care which requires regulated professional, organisational and procedural protocols.

\section{The art and science of nursing practice}

Nursing practice is clearly articulated in the literature as both a science and an art (Peplau, 1987). The science of nursing is described as evidence-based practice, which is in line with codes of conduct and ethical standards of practice (Vega \& Hayes, 2019). Despite an academic focus on clinical excellence being crucial, striking a balance with the art and science of nursing is something that is paramount within a higher education curriculum. The art of nursing is described as the core components of compassion, communication, and quality of care, as well as the biopsychosocial needs, spiritual needs, and cultural determinants of health (Lawrence, 2012; Vega \& Hayes, 2019). Furthermore, nurses have articulated that the increasing complexity of medical tasks and procedures have, over time, resulted in nurses having to prioritise clinical practice over relational care, for example play interactions when nursing in a paediatric setting (Parson, 2008). These 'soft skills' are often described as more difficult to teach within a nursing curriculum (Vega \& Hayes, 2019). Peplau (1987) described nurses as being valued and demonstrating good, 
honest and moral behaviours. Thus, the academic needs to focus on educational methods that incorporate these values, as well as the art and the science, within higher education courses, individual units and classes.

\section{The art and science of nursing education: Andragogy}

From the perspective of educating future nursing graduates, the authors wish to showcase the importance of setting the scene for optimal learning conditions as well as modelling the TPoP e.g. empathy and moral development (Schaefer \& Drewes, 2014). This can be considered from a reciprocal and holistic perspective, i.e. from a student's and the educator's biopsychosocial, environmental and moral stance. If we as educators are not able to demonstrate care, there is no modelling on offer for the students. Nursing professionals who uphold strong ethical values need to be the conduit to instil therapeutic soft skills for undergraduate nursing students.

\section{Integration of play and playfulness into nursing education}

The integration of play-based educational approaches allows for an innovative discourse to emerge, whereby learning is experienced in a socially engaged state. For example, Allen, Brown, Duff, Nesbitt, and Hepner (2013) support the use of interactive simulations and the inclusion of role-play to ensure culturally appropriate learning. Lawrence (2012) discusses that artistic expression transforms learning and when the individual's imagination and creativity is activated, it is transformative for nursing education. It is at this point that the art and science of nursing practice intersects with andragogy and the integration of play and playfulness in nursing education (see Figure 1).

\section{Figure 1}

Integrating play and playfulness into nursing education. 


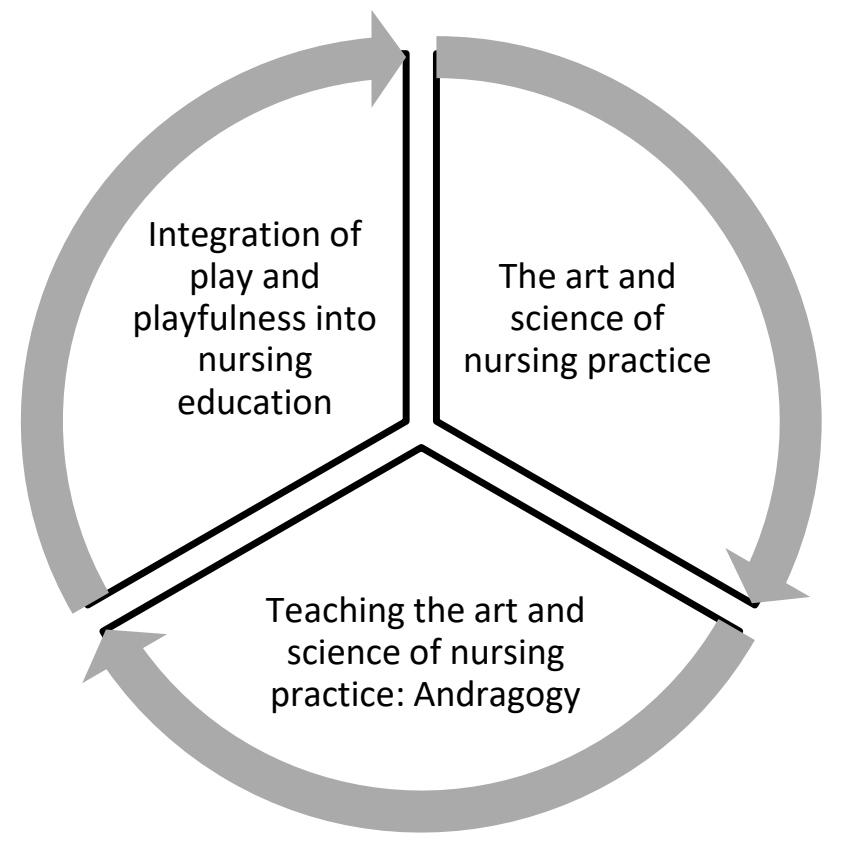

Play

Play is difficult to define, yet it has been dissected into elements, characteristics, and according to its function. Eberle (2014) identifies six basic elements of play, namely: anticipation; surprise; pleasure; understanding; strength; and poise. These elements are useful for the academic to consider, including the emotional, physical, intellectual and playful dimensions that may be incorporated into the manner in which educational material is presented (see Eberle, 2014, for further reading). Play is a process, with a before and an after, and a safe way to trial ideas which may elicit a range of emotions. Authors describe play as characteristics, for example, that play is fun, spontaneous, episodic, voluntary, active, symbolic, meaningful, rule governed and has no extrinsic goals (Dockett \& Fleer, 1999; Garvey, 1977; Stagnitti, Unsworth, \& Rodger, 2000). Bruner (1977, cited in Dockett \& Fleer, 1999, p. 17) states that:

the main characteristic of play - whether child or adult - is not its content, but its mode. Play is an approach to action, not a form of activity.

Thus, play includes and combines multidimensional elements, functions, and behaviours, as well as a characteristic mind-set. This highlights the importance of the academic to practice playfulness within their teaching role. According to Eberle (2009), play is our brain's favourite way of learning and therefore the entry point to strengthen learning. However, the first step in building upon a nursing discourse of play andragogy is to acknowledge the complexity of play as a concept and to move onto more specific understandings in the application of play in relation to student experiences of learning. To establish this within the nursing discourse of play and approach in education, it is important to understand the therapeutic and educative value of play. 


\section{EPR play development}

Jennings (2010), in her developmental play therapy model, sequenced play across the Embodiment Projective - Role (EPR) paradigm, which charts progression in play abilities.. Prendiville (2021) proposed that these stages are linked to areas of personal identity (see Table 1). The below table depicts the adaptation from personal development to professional identity and the application for practice and nursing education.

\section{Table 1}

Integrating Jennings' EPR development of play and Prendiville’s (2021) area of personal identity and adapted for playful interactions within nursing education.

\begin{tabular}{|c|c|c|c|c|}
\hline $\begin{array}{l}\text { Type of } \\
\text { play }\end{array}$ & $\begin{array}{l}\text { Area of } \\
\text { personal } \\
\text { identity }\end{array}$ & $\begin{array}{l}\text { Examples of } \\
\text { playful } \\
\text { interactions }\end{array}$ & $\begin{array}{c}\text { Application for nursing } \\
\text { practice }\end{array}$ & $\begin{array}{c}\text { Examples in nursing } \\
\text { education }\end{array}$ \\
\hline $\begin{array}{l}\text { Embodiment } \\
\text { play }\end{array}$ & $\begin{array}{l}\text { Physical } \\
\text { identity }\end{array}$ & $\begin{array}{l}\text { Physical } \\
\text { movement and } \\
\text { sensory } \\
\text { exploration. } \\
\text { (Play therapy } \\
\text { techniques that } \\
\text { target brain stem } \\
\text { function) }\end{array}$ & $\begin{array}{l}\text { Where the student is } \\
\text { required to explore sensory } \\
\text { or self-regulation in order to } \\
\text { reflect on the internal } \\
\text { feelings of nursing practice. } \\
\text { For example, how does it feel } \\
\text { to give an injection for the } \\
\text { first time? } \\
\text { Level of trust in own body to } \\
\text { undertake tasks such as } \\
\text { transferring a patient. }\end{array}$ & $\begin{array}{l}\text { Reflection of own early } \\
\text { life development (what is } \\
\text { coming up for the student } \\
\text { through learning this } \\
\text { content). } \\
\text { Play based education: } \\
\text { colour in a body outline } \\
\text { with the colours that } \\
\text { identify the feelings in } \\
\text { different areas of the } \\
\text { body. }\end{array}$ \\
\hline $\begin{array}{l}\text { Projective } \\
\text { play }\end{array}$ & $\begin{array}{l}\text { Emotional } \\
\text { identity }\end{array}$ & $\begin{array}{l}\text { Player projects } \\
\text { meaning onto } \\
\text { something } \\
\text { outside the body. } \\
\text { Small world play, } \\
\text { artistic } \\
\text { expressions, } \\
\text { creating a story. }\end{array}$ & $\begin{array}{l}\text { To be aware of their own } \\
\text { personal thoughts and } \\
\text { feelings of themselves and } \\
\text { become aware of } \\
\text { unconscious bias in relation } \\
\text { to self and others. } \\
\text { For example, how does it feel } \\
\text { to nurse someone from a }\end{array}$ & $\begin{array}{l}\text { Play based education: } \\
\text { sand tray experiential } \\
\text { focusing on delivering } \\
\text { specific nursing care to } \\
\text { this population. }\end{array}$ \\
\hline
\end{tabular}




\begin{tabular}{|c|c|c|c|c|}
\hline & & $\begin{array}{l}\text { (Play therapy } \\
\text { techniques that } \\
\text { target limbic } \\
\text { system function) }\end{array}$ & $\begin{array}{l}\text { marginalised and vulnerable } \\
\text { population group (someone } \\
\text { who demonstrates } \\
\text { aggressive behaviours). }\end{array}$ & \\
\hline Role play & $\begin{array}{l}\text { Role } \\
\text { identity }\end{array}$ & $\begin{array}{l}\text { Include } \\
\text { pretending to } \\
\text { take on another } \\
\text { role, e.g. drama or } \\
\text { improvisation. } \\
\text { (Play therapy } \\
\text { techniques that } \\
\text { target cortical } \\
\text { function - cerebral } \\
\text { cortex) }\end{array}$ & $\begin{array}{l}\text { Where the student can } \\
\text { engage in role-play in } \\
\text { preparation to perform } \\
\text { specific nursing skills. } \\
\text { Identifying as a nurse. } \\
\text { Role-playing as a nurse and } \\
\text { patient. } \\
\text { Reflecting on practice in } \\
\text { roles. }\end{array}$ & $\begin{array}{l}\text { Play based education: role } \\
\text { play with peers how they } \\
\text { would playfully engage } \\
\text { an adolescent to prepare } \\
\text { them for a procedure. }\end{array}$ \\
\hline
\end{tabular}

For the academic to engage students in range of play-based learning experiences it is important to consider the scope of play sequenced through the EPR model, as well as associated strategies. Despite nursing academics accepting role-play as a useful tool to promote learning within simulations (Allen et al., 2013), embodiment and projective play are less common, however there is scope to develop these further. Embodiment play could be utilised in andragogy through, for example, types of sensory regulatory play. Examples could include: guided imagery; breath work; stretching and moving; the use of essential oils; music; and dance. This would assist with self-regulation to either energise or calm students in readiness to learn. The next step in the sequence is projective play.

A type of projection, small world play, is the use of miniatures or symbols to represent something else. Miniatures are visual, tactile objects, which can be used in their true sense or with symbolic meaning to create play-based narratives and make meaning via symbolic representation and object substitution. For example, a stone represents a heart that has stopped beating or is used within the play narrative as a seat in a garden. Using symbols in projective play, which is representational thinking, requires and assists with the ability to conceptualise abstract concepts (Goldingay et al., 2020). Miniatures can be used to simulate or enact case scenarios, to think dynamically about potential nursing problems, or re-count or re-enact previous experiences to support cognitive processing or individual or group reflection (Goldingay et al., 2020; Robinson, Schaap, \& Avoseh, 2018). Projective small world play with miniatures in the teaching of nursing 
concepts has had a significant positive effect on student learning outcomes as evidenced anecdotally and through student evaluations at the end of each trimester.

Miniatures have been used in the higher education setting in a multitude of ways. Miniatures can be introduced as icebreakers to build safe supportive relationships and enhance communication, especially in relation to the many sensitive and intimate topics presented in nursing. Ackland-Tilbrook and Warland (2015) speak of the importance of engaging nursing students in meaningful activities to encourage deep learning and dynamic interactions through innovative teaching styles. Miniatures are useful to provide a visual and tactile experience, which can assist to deeply embed complex concepts. Ackland-Tilbrook and Warland (2015) used Visually Authentic Learning Tools (VALT TM) to allow students to visualise a midwifery scenario with the use of a shoe box and pregnant dolls. This use of miniatures was found beneficial in assisting students to understand the complexities of bleeding in pregnancy as well as skill development, clinical reasoning and decision making skills (Ackland-Tilbrook \& Warland, 2015). Goncu and Perone note the importance of pretend play across the lifespan (Goncu \& Perone, 2005; Perone \& Goncu, 2014). In projective small world pretend play, miniature replicas of people, animals, buildings, furnishings and other relevant toys are utilised to simulate real life scenarios (Chazan, 2002; Jennings, 2010).

Wilson (2018) speaks of the importance of learning core nursing skills and teamwork skills in a playful fun way. For example, role-play has been used to educate nursing students in an interactive way, trust games to build team relationships, and ice breaker activities, such as nurse bingo, to encourage a playful environment, are included in the top ten list of nursing games (Wilson, 2018). Role-play in nursing simulations is accepted and evidenced within the literature, particularly in simulation settings in higher education nursing programs (McAllister et al., 2013; Nilsson, 2010; Reid Searl et al., 2014; Tilbrook, Dwyer, Reid-Searl, \& Parson, 2017a) Allen et al. (2013) modified an undergraduate nursing curriculum to include role-play and experiential learning to promote inclusive cross-cultural anti-discriminatory teaching approaches. McAllister et al. (2013) discuss the many creative, fun, imaginative ways simulations can be conducted using role-play approaches including puppet play. Reid Searl et al. (2014) utilises interpersonal theory to teach humanistic skills to students through masked education simulation, see for example, Reid-Searl (2014) on the following YouTube link (https://www.youtube.com/watch?v=Ii6RxDD9br8). Reid Searl et al. (2014) also describes puppetbased learning as a powerful medium to link theory to practice and bring interpersonal theory to life. Tilbrook, Dwyer, Reid-Searl, and Parson (2017b) strongly recommend the use of puppet play in paediatric nursing, as well as other techniques that incorporate play therapy principles through simulation and higher education learning. Academics need to carefully consider when to integrate and align the curriculum to sequentially scaffold playful engagement (see Figure 2). 


\section{Figure 2}

Examples of types of play-based activities

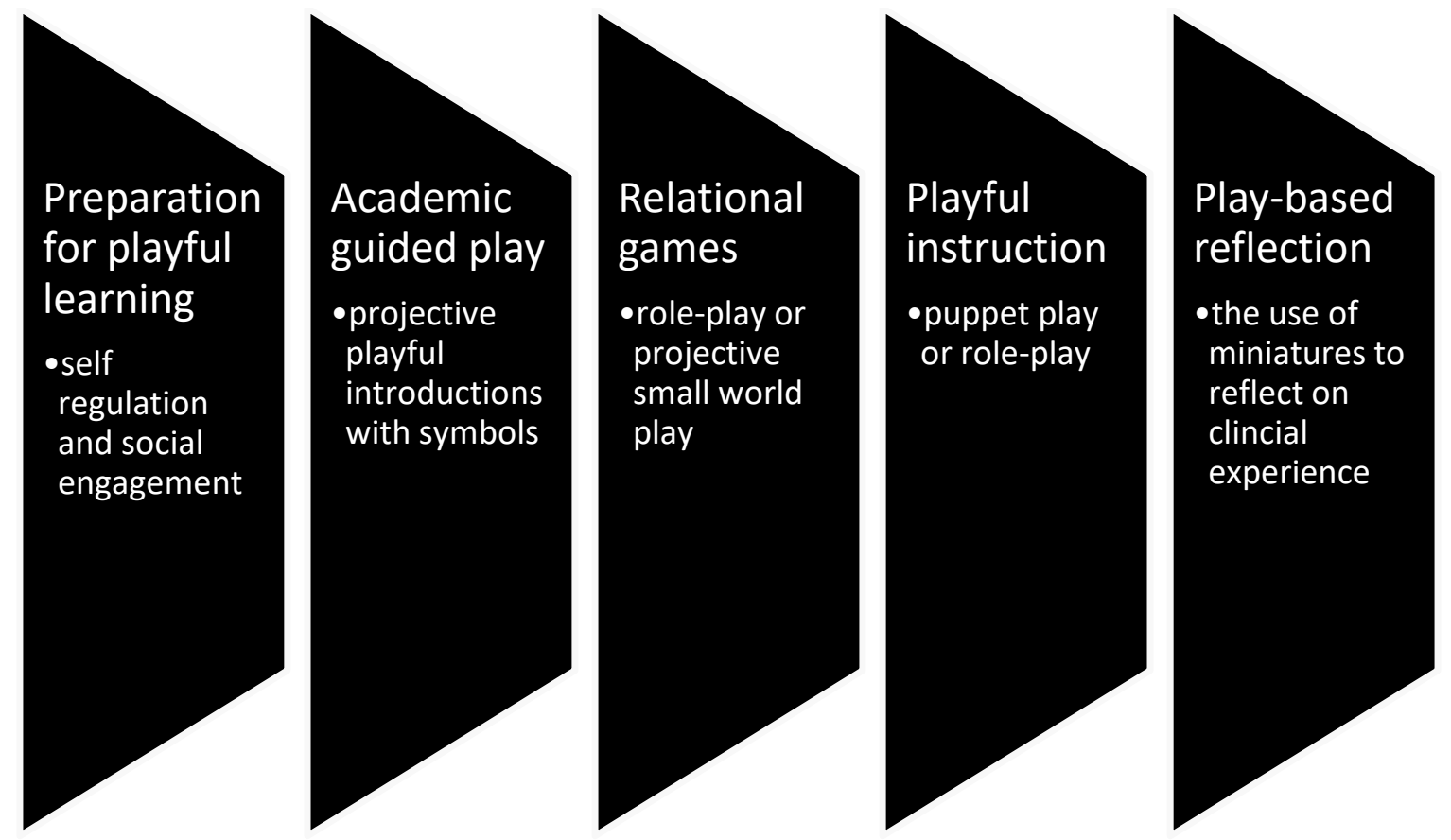

The EPR schema is one way to align teaching examples; another way is to consider play based education through the therapeutic powers of play lens.

\section{The therapeutic powers of play}

The therapeutic powers of play are used in play therapy to identify the specific agents that facilitate change in a psychotherapeutic intervention. Similarly, the TPoP can be used to act as the medium to initiate, facilitate or strengthen their therapeutic effect (Schaefer \& Drewes, 2014). Schaefer and Drewes (2014) presented a list of twenty core agents of change in four categories, namely that play: 1) facilitates communication; 2) fosters emotional wellness 3) enhances social relationships and 4) increases personal strengths. The specific TPOPs are listed within the four categories as outlined in the figure below (see Figure 3) and will be expanded upon to align specific agents of change for transformative learning. 


\section{Figure 3}

The therapeutic powers of play

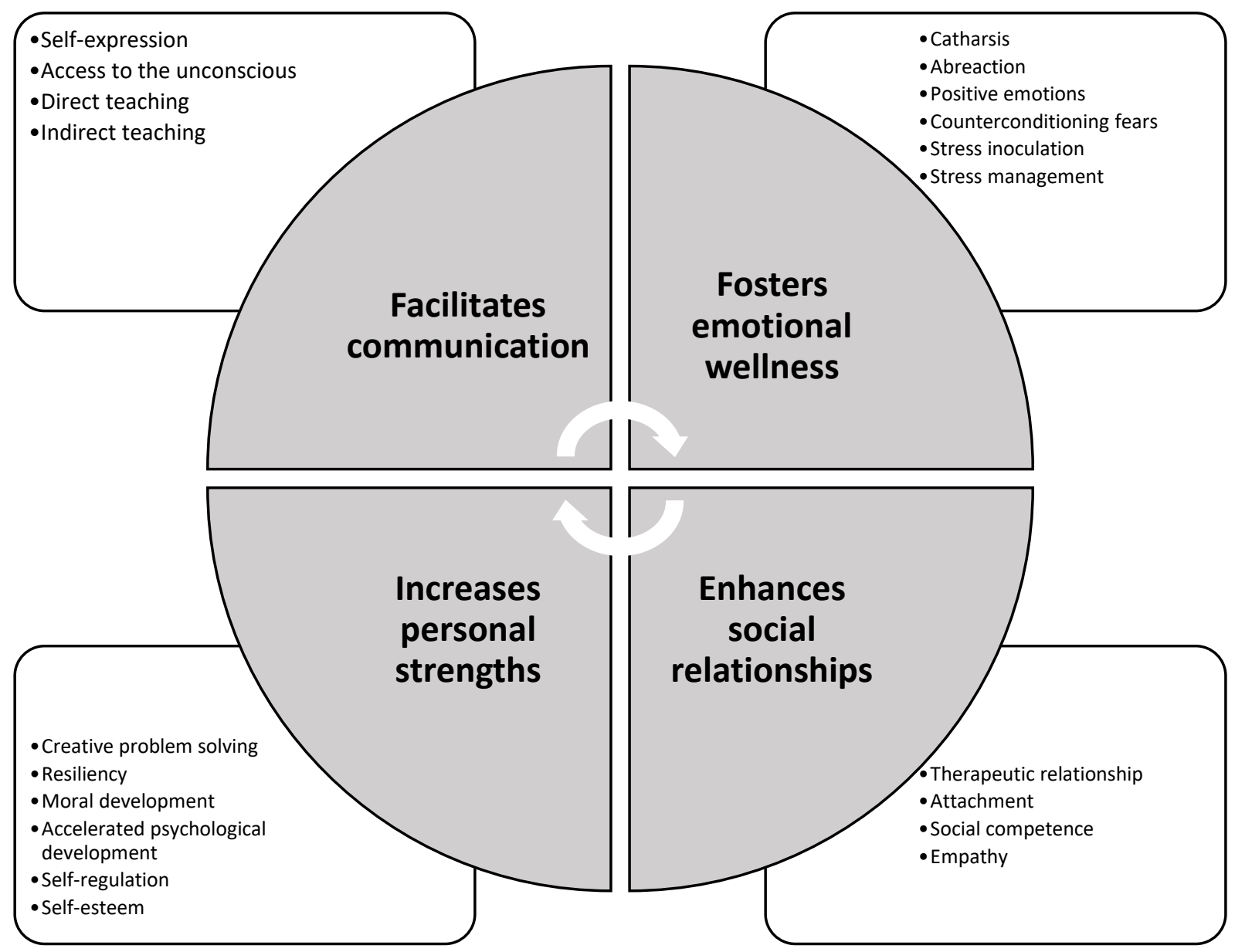

Note: Graphic created by Judi Parson adapted from C.E. Schaefer \& A.A. Drewes (2014). The therapeutic powers of play: 20 core agents of change ( 2 nd ed.). Hoboken, N.J: John Wiley.

\section{Facilitates communication}

The use of play-based approaches in teaching is powerful because play is recognized as a transformative agent of change which facilitates communication, including self-expression, access to the unconscious, and both direct and indirect teaching (Schaefer \& Drewes, 2014). Play in and of itself is a form of self-expression. Play provides access to the unconscious to use defence mechanisms such as projection, symbolism and pretence as a process to communicate meaning (Schaefer, 2020). Play provides opportunities for direct teaching, such as learning a new skill, or indirect teaching, such as the use of reflective role-play to introduce a new concept. 


\section{Fosters emotional wellness}

Catharsis, the next specific TPoP is of importance for nurses because it is associated with the release of strong emotions such as stress and anxiety. Nurses may find it cathartic to learn specific healthy ways to engage in self-care and manage potentially stressful work conditions. Abreaction involves displacing previously frightening or traumatic experiences onto another source. This could be useful in teaching to showcase prior memories that could impact on nursing care practice in the future. Clearly, play is fun and play evokes positive emotions. The simple act of smiling, laughing and demonstrating positive emotions fosters a sense of well-being. Play can be used for countercondition fears, as fear of blood, needles and medical treatment which often evoke previously held understandings of negative thoughts and feelings regarding hospitals, medical or dental treatment. Another way to address this is via stress inoculation whereby nursing students are introduced to specific procedures in a playful way prior to delivering the same procedure to a child or adult patient. Finally, stress management is important for the student nurse to experience specific games to reduce vocational distress. (For more information regarding the specific therapeutic powers of play see Schaefer and Drewes, 2014).

\section{Enhances social relationships}

This section refers to the therapeutic relationship, and creative play-based learning enhances social relationships, empathy, self-esteem, theory of mind, creative problem solving and social competence which are crucial skills for nurses to develop (Drewes \& Schaefer, 2014; Goldingay et al., 2020; Goldingay et al., 2015; Stagnitti, 2016). Traditional games and online games are utilised to enhance nursing skills and are now popular for learning and team building in developing social and relational skills (Wilson, 2018). Amongst other skills, pretend play also improves the ability to show empathy and to see the perspectives of others therefore increasing social competence (Goldingay et al., 2020; Goldingay et al., 2015; Stagnitti, 2016).

\section{Increases personal strengths}

Play actives the imagination and facilitates creative problem solving, a core graduate learning outcome for all nurses. Utilising a relational experiential play pedagogy within education also supports stress inoculation and self-care skills (Bemis, 2014; Cavett, 2014; Drewes \& Schaefer, 2014; Farley \& Jacobwitz, 2019; Reid Searl et al., 2014). Additionally, resiliency is paramount for nursing education to address as a protective factor in order to counter reactions that nurses will inevitably experience. For example, nurses must care for people across the lifespan and in relation to critical life and death health scenarios which is confronting and often 
outcomes may be unexpected and difficult. The playful academic may utilise puppets to explore moral development and ethical decision making to consider various points of view in a safe and accessible way. As such, play facilitates an accelerated psychological development to extend scenarios and explore more complex possibilities without concerns or worries for potential mistakes in real life. To care for patients or to engage in learning the student must be able to self-regulate to control their own impulses that may be either a hyperor hypo-aroused state. Finally, self-esteem is the way that an individual thinks, feels and acts based on belief and acceptance and respect for oneself (Schaefer, 2020). (For further information on the TPoP see YouTube link (Parson \& Renshaw, 2017) (https://www.youtube.com/watch?v=wuu59E97igU).

As stated earlier, play is the brain's favourite way of learning (Eberle, 2009) and therefore knowledge of neuroscience also assists to frame play-based andragogy. When utilising the EPR and the TPoP models it is important to consider neurobiological development as a pathway to learning. Importantly, the playful academic works to create a safe environment for students, building trust and ensuring students feel confident, respected, and autonomous learners.

\section{Creating neurobiological safety in education}

In 1977, George Engle and Jon Romano proposed that health could not be purely determined as biological (Fava \& Sonino, 2017). To view health with such a lens would be neglecting the social, emotional and environmental factors, which impact us as humans. Nursing over time has transitioned from the hegemonic biomedical model to a more holistic biopsychosocial model (Turner, 1987). When considering the biological perspective, the body must be ready to receive information. Maslow's (1943) hierarchy of needs provides a baseline framework for individuals to consider that they have met their basic physical needs, such as hunger, thirst or tiredness, in the first instance. Once this level is attained then the next level, the individual needs to feel safe and secure. This level is important as it then aligns with neuroscientific literature and the states of arousal. Neuroscience informs the way educators may set the conditions to optimise and enhance engagement in learning through creating a safe environment. It is not possible to be in a receptive state and ready to learn when a student's attention is focused on something else - particularly when the polyvagal system is activated via a threat or fear (Porges, 2017). If the learning environment is not perceived as safe, then students may find themselves in a hyper or hypo aroused state (Van der Kolk, 2015). Van Der Kolk discusses the needs for safety, relaxation and true reciprocity in order for individuals to experience the interconnected neurobiology between each other. The aim is to use creativity and the TPoP to provide the safe and optimal learning conditions and thus keeping students in a socially engaged state (Kestly, 2014). This aligns with the optimal conditions that are used to enhance the relationship found in play therapy. 


\section{Conclusion}

Whilst play is difficult to define, elements, characteristics and the functional aspects of play are well documented. Play and playfulness enhance learning through creating neurobiological safety within the teaching and learning environment. The EPR and TPOP models have been introduced to expand on nursing education through play-based andragogy. Contemporary experiential, culturally safe, transformative learning approaches to teaching with creative, interpersonal, relational, play pedagogies and andragogy are now sought after by academics and students alike (Baumer \& Radsliff, 2010; McAllister et al., 2013; Murphy \& Brown, 2012; Reid Searl et al., 2014; Robinson et al., 2018). The numerous benefits to students have been presented and the potential benefits may extend to patients throughout clinical placement and into each student's future nursing career. It is hypothesised that the playful academic's inclusion of play will improve student experiences and teaching outcomes within a higher education nursing context.

\section{References}

Ackland-Tilbrook, V., \& Warland, J. (2015). Open the VALT ${ }^{\mathrm{TM}}$ : Creation and application of a visually authentic learning tool. Nurse Education in Practice, 15(3), 249-252. doi: 10.1016/j.nepr.2015.01.014

Allen, J., Brown, L., Duff, C., Nesbitt, P., \& Hepner, A. (2013). Development and evaluation of a teaching and learning approach in cross-cultural care and antidiscrimination in university nursing students. Nurse Education Today, 33(12), 1592-1598. doi: 10.1016/j.nedt.2012.12.006

Baumer, S., \& Radsliff, K. (2010). Playworlds of children and adults: Cultural perspectives on play pedagogy. Mind, Culture, and Activity, 17(1), 11-13. doi: 10.1080/10749030903348755

Bemis, K., S. (2014). Stress Management. In C. E. Schaefer \& A. A. Drewes (Eds.), The therapeutic powers of play: 20 core agents of change ( $2^{\text {nd }}$ ed.). Hoboken, New Jersey: John Wiley \& Sons, Inc.

Cavett, A. M. (2014). Stress Inoculation. In C. E. Schaefer \& A. A. Drewes (Eds.), The therapeutic powers of play: 20 core agents of change ( $2^{\text {nd }}$ ed.). Hoboken, New Jersey: John Wiley \& Sons, Inc.

Chazan, S. E. (2002). Profiles of play: assessing and observing structure and process in play therapy. London, Philadelphia: Jessica Kingsley.

Commonwealth of Australia. (2013). Appendix iv: History of Commonwealth involvement in the nursing and midwifery workforce. Retrieved May 5, 2020, from https://www1.health.gov.au/internet/publications/publishing.nsf/Content/work-reviewaustralian-government-health-workforce-programs-toc appendices appendix-iv-historycommonwealth-involvement-nursing-midwifery-workforce

Culatta, R. (2020). Andragogy (Malcolm Knowles). Retrieved September 7, 2020, from https://www.instructionaldesign.org/theories/andragogy/ 
Dockett, S., \& Fleer, M. (1999). Play and pedagogy in early childhood: Bending the rules. Sydney: Harcort.

Drewes, A. A., \& Schaefer, C. E. (2014). How play therapy causes therapeutic change. In C. E. Schaefer \& A. A. Drewes (Eds.), The therapeutic powers of play: 20 core agents of change $\left(2^{\text {nd }}\right.$ ed.). Hoboken, New Jersey: John Wiley \& Sons, Inc.

Eberle, S. G. (2014). The elements of play: Toward a philosophy and a definition of play. American Journal of Play, 6(2), 214-233.

Eberle, S. G. (2009) TEDxRochester - Scott Eberle - 11/02/09 [Video file]. Retrieved from https://www.youtube.com/watch?reload=9\&v=jApW2tilJOI

Farley, C. L., \& Jacobwitz, J. (2019). Cooking up a delicious experiential learning activity. Nurse Education Today, 77, 24-26. doi: 10.1016/j.nedt.2019.03.003

Fava, G. A., \& Sonino, N. (2017). From the lesson of George Engel to current knowledge: The biopsychosocial model 40 years later. Psychotherapy and Psychosomatics, 86(5), 257-259. doi: $10.1159 / 000478808$

Garvey, C. (1977). Play: The developing child. Cambridge, Massachusetts: Harvard University Press.

Goldingay, S., Stagnitti, K., Dean, B., Robertson, N., Francis, E., \& Davidson, D. (2020). Storying Beyond Social Difficulties with Neuro-Diverse Adolescents : The 'Imagine, Create, Belong' Social Development Program. New York: Routledge.

Goldingay, S., Stagnitti, K., Sheppard, L., McGillivray, J., McLean, B., \& Pepin, G. (2015). An intervention to improve social participation for adolescents with autism spectrum disorder: Pilot study. Developmental Neurorehabilitation, 18(2), 122-130. doi: $10.3109 / 17518423.2013 .855275$

Goncu, A., \& Perone, A. (2005). Pretend Play as a Life-span Activity. Topoi: An International Review of Philosophy (2), 137.

International Council of Nurses (ICN). (2008). Nursing definitions. Retrieved August 25, 2020, from https://www.icn.ch/

Jennings, S. (1999). An introduction to developmental playtherapy. London: Jessica Kingsley Publishers. .

Jennings, S. (2010). Embodiment-Projection-Role: A developmental model for the play therapy method. In C. E. Schaefer, J. McCormick \& A. Ohnogi (Eds.), International handbook of play therapy: advances in assessment, theory, research and practice (pp. 65-76). Jason Aronson.

Kestly, T. A. (2014). The interpersonal neurobiology of play: brain-building interventions for emotional well-being. New York: W.W. Norton \& Company.

Knowles, M. S. (1984). The adult learner : a neglected species (3 ${ }^{\text {rd }}$ ed.). Gulf Pub. Co., Book Division.

Lawrence, R. (2012). Transformative learning through artistic expression, getting out of our heads. In E. W. Taylor \& P. Cranton (Eds.), The handbook of transformative learning : theory, research, and practice. Jossey-Bass higher and adult education series.

Mackey, A., \& Bassendowski, S. (2017). The history of evidence-based practice in nursing education and practice. Journal of Professional Nursing, 33(1), 51-55. doi: 10.1016/j.profnurs.2016.05.009

Margaret, M., Jennene, G., Madsen, W., \& Godden, J. (2010). Generating ideas for the teaching of nursing's history in Australia. Collegian, 17(1), 13-22. doi: 10.1016/j.colegn.2009.06.001 
Maslow, A. H. (1943). A theory of human motivation. Psychological Review, 50(4), 370-396. doi: $10.1037 / \mathrm{h} 0054346$

McAllister, M., Levett-Jones, T., Downer, T., Harrison, P., Harvey, T., Reid-Searl, K., . . Calleja, P. (2013). Snapshots of simulation: creative strategies used by Australian educators to enhance simulation learning experiences for nursing students. Nurse Education in Practice, 13(6), 567572. doi: 10.1016/j.nepr.2013.04.010

Murphy, M., \& Brown, T. (2012). Learning as relational: intersubjectivity and pedagogy in higher education. International Journal of Lifelong Education, 31(5), 643-654. doi: $10.1080 / 02601370.2012 .700648$

Nilsson, M. E. (2010). Creative pedagogy of play - The work of gunilla lindqvist. Mind, Culture, and Activity, 17(1), 14-22. doi: 10.1080/10749030903342238

Parson, J. (2008). Integration of procedural play for children undergoing cystic fibrosis treatment: A nursing perspective. Central Queensland University.

Parson, J. (2017). Puppet play therapy: Integrating Theory, Evidence and Action (ITEA) (pp. Adapted from C.E. Schaefer and A.A. Drewes (2014) The therapeutic powers of play: 2020 core agents of change. ). Presented at International Play Therapy Study Group Champneys Forest Mere UK.

Parson, J., \& Renshaw, K. (2017). Therapeutic Powers of Play.

Peplau, H., E. (1987). The Art and Science of Nursing: Similarities, Differences, and Relations. Nursing Science Quarterly, 88(01), 8-15.

Perone, A., \& Goncu, A. (2014). Life-Span Pretend Play in Two Communities. Mind, Culture $\mathcal{E}$ Activity, 21(3), 200-220. doi:

10.1080/10749039.2014.922584\&sid=libx:deakin:doi\&genre=article

Porges, S. (2017). The Pocket Guide to the Polyvagal Theory: The Transformative Power of Feeling Safe. New York: W. W. Norton \& company.

Prendiville, E. (2021). The EPR Informed Psychotherapist. In E. Prendiville \& J. Parson (Eds.), Clinical applications of the therapeutic powers of play: case studies in child and adolescent psychotherapy. Oxon: Routledge.

Reid-Searl, K. (2014). From one space to another: Kerry Reid Searl at TEDxNoosa 2014 [Video file]. Retrieved from https://www.youtube.com/watch?v=Ii6RxDD9br8)

Reid Searl, K., McAllister, M., Dwyer, T., Krebs, K. L., Anderson, C., Quinney, L., \& McLellan, S. (2014). Little people, big lessons: an innovative strategy to develop interpersonal skills in undergraduate nursing students. Nurse Education Today, 34(9), 1201-1206. doi: 10.1016/j.nedt.2014.04.004

Robinson, D., Schaap, B. M., \& Avoseh, M. (2018). Emerging themes in creative higher education pedagogy. Journal of Applied Research in Higher Education, 10(3), 271-282. doi: 10.1108/JARHE-08-2017-0099

Rogers, C. R. (1969). Freedom to learn : a view of what education might become: C. E. Merrill Pub. Co.

Schaefer, C. E. (Producer). (2020). The therapeutic powers of play: Online training. Retrieved from https://the-play-therapy-training-institute.teachable.com/courses/

Schaefer, C. E., \& Drewes, A. A. (2014). The therapeutic powers of play : 20 core agents of change. $\left(2^{\text {nd }}\right.$ ed.). Hoboken, New Jersey: John Wiley \& Sons, Inc. 
Stagnitti, K. (2016). Play, narrative, and children with Autism. In S. L. Douglas \& L. Stirling (Eds.), Children's play, pretense, and story: studies in culture, context, and autism spectrum disorder (pp. 51-71). New York: Routledge.

Stagnitti, K., Unsworth, C., \& Rodger, S. (2000). Development of an assessment to identify play behaviours that discriminate between the play of typical preschoolers and preschoolers with pre-academic problems. Canadian Journal of Occupational Therapy / Revue Canadienne D'Ergothérapie, 67(5), 291-303.

Tilbrook, A., Dwyer, T., Reid-Searl, K., \& Parson, J. A. (2017a). A review of the literature - The use of interactive puppet simulation in nursing education and children's healthcare. Nurse Education in Practice, 22, 73-79. doi: 10.1016/j.nepr.2016.12.001

Tilbrook, A., Dwyer, T., Reid-Searl, K., \& Parson, J. A. (2017b). A review of the literature - the use of interactive puppet simulation in nursing education and children's healthcare: Elsevier.

Turner, B., S. (1987). Medical Power and Social Knowledge. London: Sage Publications.

Van der Kolk, B. (2015). The Body Keeps The Score: Mind, Brain and Body in the Transformation of Trauma. Great Britain: Penguin Books.

Vega, H., \& Hayes, K. (2019). Blending the art and science of nursing. Nursing, 49(9), 62-63. doi: 10.1097/01.NURSE.0000577752.54139.4e

Wilson, B. (2018). 9 Fun and Educational Nursing Games. Retrieved May 11, 2020, from https://thenerdynurse.com/9-fun-and-educational-nursing-games/ 